\title{
POLPA CONGELADA DE ACEROLA: EFEITO DA TEMPERATURA SOBRE OS TEORES DE ANTOCIANINAS E FLAVONÓIS TOTAIS ${ }^{1}$
}

\author{
VERA LÚCIA ARROXELAS GALVÃO DE LIMA², ENAYDE DE ALMEIDA MÉLO, LUECI DOS SANTOS LIMA4, \\ DAISYVÂNGELA E. DA SILVA LIMA ${ }^{5}$
}

\begin{abstract}
RESUMO- Com o objetivo de avaliar a estabilidade das antocianinas e a ação protetora dos flavonóis em polpas de acerola armazenadas sob congelamento, foram montados dois ensaios com acerolas colhidas em pleno estádio de maturação. No ensaio I, a polpa foi obtida de acerolas de uma seleção conhecida e, no ensaio II, de acerolas de várias plantas, cultivadas em um pomar particular. O delineamento experimental foi inteiramente casualizado, com três repetições e dois fatores: (a) polpas de diferentes origens; e (b) seis meses de congelamento. A intervalos de 30 dias, unidades amostrais de $30 \mathrm{~g}$ foram coletadas ao acaso e submetidas a determinação quantitativa de antocianinas e flavonóis totais. Ao final do experimento, houve redução nos teores de antocianinas totais da ordem de 4,30\% e de 3,76\% e nos teores de flavonóis totais de 13,44\%, e 14,90\% nos ensaios I e II respectivamente. O menor percentual de redução do teor de antocianinas na polpa do ensaio II decorreu, possivelmente, da ação protetora dos flavonóis que considerando o teor dos pigmentos antociânicos, se encontravam em maior concentração nesta polpa do que na polpa do ensaio I. Termos para Indexação: Malpighia emarginata D.C., antocianinas, flavonóis, estabilidade.
\end{abstract}

\section{FROZEN ACEROLA PULP: TEMPERATURE EFFECT ON TOTAL ANTHOCYANINS AND FLAVONOLS}

ABSTRACT- The aim of this work was to evaluate the anthocyanins stability and the flavonols protective action on acerola pulp during frozen storage. Two assays were carried out with completely mature acerola. For the first assay, the pulp was obtained from a known selection of acerola and for the second, from different trees grown in a particular crop. These experiments were completely randomised with three repetitions and two factors: (a) pulp from different origins and (b) six months frozen storage. At each 30 days, samples units (30g) were randomly collected and analysed in order to determine total anthocyanins and flavonols content. At the end of the storage period, the first assay lost 4,3\% and the second, 3,76\% of the total anthocyanins content and $13,44 \%$ and $14,90 \%$ of the total flavonols content, respectively. On assay II, the lower reduction of percentage of anthocyanins was probably due to flavonols protective action.

Index Terms: Malpighia emarginata D.C , anthocyanins, flavonols, stability

\section{INTRODUÇÃO}

No reino vegetal, as antocianinas são pigmentos responsáveis por uma variedade de cores que variam do vermelho vivo ao violeta e azul e os flavonóis são pigmentos de cores branca ou amarela clara. Quimicamente, esses pigmentos são compostos fenólicos pertencentes ao grupo dos flavonóides (Bobbio \& Bobbio, 1995). Os flavonóis são importante por atuarem na copigmentação das antocianinas através de mecanismo de complexação intermolecular, tornando mais estável a molécula antociânica. Dentre os compostos que exibem esta ação, os flavonóis são os mais eficazes (Malien-Aubert et al., 2001). A cor vermelha da acerola, no estádio maduro, decorre da presença de antocianinas. Silva et al. (1998) citam a malvidina, pelargonidina e cianidina como as principais antocianidinas presentes em acerola.

As antocianinas, pigmentos muito instáveis, podem ser degradadas durante o processamento e a estocagem de alimentos com conseqüente alteração da cor. O congelamento, um dos principais métodos de conservação de frutos, bastante utilizado na conservação da acerola, descaracteriza completamente a coloração natural do fruto (Alves et al., 1997). Em suco de acerola pasteurizado, também ocorre modificação em sua coloração, que passa de vermelho-brilhante a amarela (Conceição,1997). Este trabalho teve como objetivo averiguar o comportamento dos teores de antocianinas e flavonóis totais em polpa de acerola armazenada sob congelamento.

\section{MATERIALEMÉTODOS}

Acerolas provenientes de dois plantios (seleção conhecida (Barbados) e não conhecida), foram colhidas de uma única planta de cada seleção, no estádio de maturação maduro, com coloração vermelha uniforme. Os frutos ( $2 \mathrm{~kg}$ de cada seleção) foram transportados para o Laboratório de Análises Físico-químicas e Sensorial de Alimentos do Departamento de Ciências Domésticas/UFRPE e imediatamente transformados em polpa, utilizando centrífuga doméstica, que foi acondicio- nada em potes plástico e armazenada sob congelamento $\left(-18^{\circ} \mathrm{C}\right)$, em "freezer" doméstico, durante 6 meses. A polpa da seleção conhecida constituiu o ensaio I, enquanto a da seleção não conhecida o ensaio II. $\mathrm{O}$ experimento foi instalado seguindo um delineamento inteiramente casualizado, em esquema fatorial 2 x 6de (tipo de seleção x tempo de armazenamento). A intervalos de 30 dias, unidades experimentais de $30 \mathrm{~g}$ foram coletadas ao acaso e submetidas a determinação quantitativa de antocianinas e flavonóis totais, utilizando o método espectrofotométrico descrito por Lees \& Francis (1972). Estas determinações foram efetuadas em triplicata e os resultados submetidos a Análise de Variância e Teste de Tukey, ao nível de 5\%, utilizando o programa estatístico "Minitab-10 for Windows".

\section{RESULTADOSE DISCUSSÃO}

Os teores iniciais de antocianinas totais dos ensaios I e II (26,23 e $14,11 \mathrm{mg} .100 \mathrm{~g}^{-1}$, respectivamente) apresentados na Tabela 1 , encontram-se na faixa dos teores deste pigmento, relatados por Paiva et al. (1999), para diferentes seleções de acerola (1,97 a 46,44 mg.100 $\left.{ }^{-1}\right)$. Embora o teor inicial de antocianinas totais da polpa do ensaio I tenha sido maior do que o do ensaio II, observou-se que, nos dois ensaios, a variação desses teores apresentou comportamento semelhante durante o período de estocagem. Ao comparar os valores encontrados no tempo inicial e final de armazenamento, evidenciou-se uma redução nos teores de antocianinas totais da ordem de 4,30\% para o ensaio I e de 3,76\% para o ensaio II.

Outros autores também detectaram redução dos pigmentos antociânicos em produtos de acerola. Matsuura (1994), determinou valores de 136,3 a 147,6 de antocianinas, expressos em mg.L.-1 (malvidina 5$\mathrm{G})$, em suco integral concentrado de acerola congelado $\left(-18^{\circ} \mathrm{C}\right)$ armazenado por 180 dias. Ao final do período de estocagem a redução no teor desses pigmentos foi da ordem de 2,79\%. Silva et al. (1999), ao armazenarem polpa de acerola sob congelamento por seis meses, sem tratamento térmico, evidenciaram um percentual de redução bem mais elevado, da

1 (Trabalho 193/2001). Recebido: 26/11/2001. Aceito para publicação: 06/09/2002.

2 Eng. Química, M. Sc., Prof. Adjunto, DCD/UFRPE, Av. Dom Manoel de Medeiros s/n, CEP 52171-900 Recife, PE. e-mail: veraarroxelas@ hotmail.com

3 Nutricionista, M. Sc., Prof. Adjunto, DCD/UFRPE

4 Economista Doméstica

5 Aluna do Curso de Graduação em Economia Doméstica, Bolsista do PIBIC/CNPq-UFRPE 
ordem de $21,74 \%$.

Os teores de flavonóis, no tempo zero de armazenamento, foram de $72 \mathrm{e} \mathrm{10,54} \mathrm{mg} \mathrm{de} \mathrm{quercetina.} 100 \mathrm{~g}^{-1}$ para os ensaios I e II, respectivamente, sendo portanto inferiores aos das antocianinas (Tabela 1). Estes resultados também foram constatados por Vendramini e Trugo (2000), em acerolas das variedades "Flor Branca" e "Okinawa", cujos teores de antocianinas totais foram de 14,90 e $12,41 \mathrm{mg}^{\circ} 100 \mathrm{~g}^{-1} \mathrm{e}$ de flavonóis totais de 11,02 e $8,82 \mathrm{mg}$ de quercetina. $100 \mathrm{~g}^{-1}$, respectivamente. Ao final do experimento, foi evidenciada uma redução nos teores destes fitoquímicos da ordem de 13,44\% para o ensaio I e 14,90\% para o ensaio II.

TABELA 1 - Teores de antocianinas e flavonóis totais em polpas de acerola armazenadas sob congelamento $\left(-18^{\circ} \mathrm{C}\right)$

\begin{tabular}{|c|c|c|c|c|c|c|c|c|}
\hline \multicolumn{9}{|c|}{ Tempo de armazenamento (dias) } \\
\hline Ensaios & Determinações & 0 & 30 & 60 & 90 & 120 & 150 & 180 \\
\hline \multirow[t]{2}{*}{ I } & $\begin{array}{l}\text { Antocianinas } \\
\text { totais } \\
\left(\mathrm{mg} \cdot 100 \mathrm{~g}^{-1}\right)\end{array}$ & $26,23 a$ & $24,32 \mathrm{c}$ & $24,66 \mathrm{~cd}$ & $27,83 a$ & $23,64 \mathrm{c}$ & $23,62 \mathrm{c}$ & $25,11 \mathrm{~d}$ \\
\hline & $\begin{array}{l}\text { Flavonóis totais } \\
(\mathrm{mg} \text { de quercetina. } \\
\left.100 \mathrm{~g}-{ }^{1}\right)\end{array}$ & $12,72 b$ & $11,38 \mathrm{c}$ & $11,16 \mathrm{c}$ & $13,41 \mathrm{a}$ & $11,16 \mathrm{c}$ & $9,10 \mathrm{~d}$ & $10,01 \mathrm{c}$ \\
\hline \multirow[t]{2}{*}{ II } & $\begin{array}{l}\text { Antocianinas } \\
\text { totais } \\
\left(\mathrm{mg} \cdot 100 \mathrm{~g}^{-1}\right) \\
\end{array}$ & $14,11 b$ & $11,14 d$ & $12,34 \mathrm{c}$ & $15,23 \mathrm{a}$ & $11,57 \mathrm{~d}$ & $11,55 \mathrm{~d}$ & $13,58 b$ \\
\hline & $\begin{array}{c}\text { Flavonóis totais } \\
\text { (mg de quercetina. } \\
\left.100 \mathrm{~g}-{ }^{1}\right)\end{array}$ & $10,54 \mathrm{a}$ & $7,97 \mathrm{~b}$ & $8,37 \mathrm{~b}$ & $10,43 a$ & $8,60 \mathrm{~b}$ & $7,24 b$ & $8,97 \mathrm{~b}$ \\
\hline
\end{tabular}

Médias com as mesmas letras na linha não diferem estatisticamente pelo teste de Tukey a $5 \%$.

No congelamento, as reações metabólicas são reduzidas, porém não totalmente inibidas (Cheftel et al., 1983). As variações nos teores de antocianinas e flavonóis totais detectadas ao longo do período de armazenamento poderiam ser justificadas pela interconversão das quatro formas estruturais de antocianinas (base quinoidal, cátion flavilium, pseudobase ou carbinol e chalcona) que, em solução aquosa ácida, se encontram em equilíbrio (Mazza \& Brouillard, 1987). Por outro lado, a degradação desses pigmentos pode também ter sido favorecida por ação enzimática, tendo em vista que a polpa produzida não foi submetida a nenhum tratamento térmico. Segundo Francis (1989), as glicosidases, também denominadas de antocianidases, hidrolisam as antocianinas liberando os açúcares e as antocianidinas as quais são mais instáveis do que as antocianinas. As fenolases podem reagir com outros compostos fenólicos, a exemplo dos flavonóis de forma mais pronunciada.

Quanto aos flavonóis, é possível que os teores mais elevados detectados em alguns meses do período de armazenamento sejam decorrentes da maior concentração de chalconas existentes na amostra. Estes compostos absorvem luz entre a região de 365 e 390 nm (Harborne, 1984), que compreende o comprimento de onda utilizado na quantificação dos flavonóis totais $(374 \mathrm{~nm})$.

Ao comparar os teores iniciais e finais de antocianinas, observase que a polpa do ensaio II apresentou uma maior estabilidade, uma vez que os valores foram estatisticamente iguais. O menor percentual de perda no teor de antocianinas na polpa desse ensaio, possivelmente, se deve a complexação desse constituinte com os flavonóis, tendo em vista que essa polpa, no tempo zero de armazenamento, apresentou um percentual maior de flavonóis em relação ao teor de antocianinas $(74,70 \%)$ quando comparado ao da polpa do ensaio I $(48,49 \%)$. A estabilidade das antocianinas ao descoramento pode ocorrer através da co-pigmentação, especialmente com os flavonóis. A associação entre as moléculas de antocianinas e flavonóis exerce um ação protetora sobre as moléculas de antocianinas (Bobbio \& Bobbio, 1995). A formação deste complexo, ou seja, a co-pigmentação, aumenta a intensidade da cor, sendo este efeito decorrente da concentração de antocianinas e do co-pigmento (Timberlake, 1980). Shrinkhande \& Francis (1974), estudando o efeito de flavonóis sobre a estabilidade do ácido ascórbico e das antocianinas em sistema modelo, verificaram que a presença de flavonóis reduziu tanto a oxidação do ácido ascórbico como também a degradação das antocianinas.

\section{CONCLUSÕES}

O congelamento promoveu redução nos teores de antocianinas e flavonóis totais das polpas de acerola dos dois ensaios; entretanto, em função do maior teor de flavonóis presente na polpa de acerola de seleções não identificadas, o pigmento antociânico apresentou maior estabilidade.

\section{AGRADECIMENTO}

À Prof ${ }^{a}$. Rosimar dos Santos Musse, do Departamento de Agronomia da UFRPE, pelo fornecimento das acerolas da seleção conhecida.

\section{REFERÊNCIASBIBLIOGRÁFICAS}

ALVES, R.E.; CHITARRA, A.B.; FREIRE,D.C.; SOUZA, K.R.; SIQUEIRA, S.M.P. de. Yellowing of frozen acerola (Malpighia emarginata) fruit. Proceedings of Interamerican Society for Tropical Horticulture, Guatemala, v.41, p.199-204, 1997.

BOBBIO, P. A.; BOBBIO, F. O. Pigmentos naturais. In: BOBBIO, P. A.; BOBBIO, F. O.(Ed.) Introdução à Química de Alimentos. $2^{a}$ ed., São Paulo: Varela, 1995. cap.6, p.191-223.

CHEFTEL, J.C.; CHEFTEL, H.; BESANÇON, P. Métodos de conservacíon. In: CHEFTEL, J.C.; CHEFTEL, H.; BESANÇON, P.(Ed.) Introduccion a la bioquímica y tecnología de los alimentos. Zaragoza: Acribia, 1983. v. 2, cap.7, p.173-202.

CONCEIÇÃO, M. P. J. Cinética de degradação térmica de antocianinas em suco de acerola (Malpighia glabra L.), 1997. 59p. Dissertação (Mestrado em Ciência e Tecnologia de Alimentos), Universidade Federal de Viçosa (UFV), Viçosa, 1997.

HARBORNE, J.B. Phenolic compounds. In: HARBORNE, J.B. (Ed) Phytochemical methods. a guide to modern techniques of plant analysis. London: Chapman and Hall, 1984. cap. 2, p.37-99.

LEES, D.H.; FRANCIS, F.J. Standardization of pigment analyses in cranberries. HortScience, Alexandria, v.7, n.1, p.83-84, 1972.

MALIEN-AUBERT, C.; DANGLES, O.; AMIOT, M.J. Color stability of commercial anthocyanin - based extract in relation of the phenolic composition. Journal of Agricultural and Food Chemistry, Washington, v.49, p.170-176, 2001.

MATSUURA, F.C.A.U. Processamento e caracterização de suco integral e concentrado congelado de acerola, 1994. 142p., Dissertação (Mestrado Tecnologia de Alimentos), Faculdade de Engenharia de Alimentos, Universidade Estadual de Campinas, Campinas, 1994.

MAZZA, G.; BROUILLARD, R. Recent developments in the stabilization of anthocyanins in food products. Food Chemistry, Oxford, v.25, p.207-225, 1987.

PAIVA, J.R., CORDEIRO, E.R., ALVES, R.E., ALMEIDA, A.S.; PINTO, S.A. Seleção e clonagem de plantas de acerola. In: ENCONTRO DE GENÉTICA DO NORDESTE, 14., 1999, Recife. Anais... Recife: Sociedade Brasileira de Genética, 1999. p.53.

SHRIKHANDE, A.J.; FRANCIS, F.J. Effect of flavonols on ascorbic acid and anthocyanin stability in model systems. Journal of Food Science, Chicago, v.39, n.5, p.904-906, 1974.

SILVA, M.F.V.; GUEDES, M.C.; MENEZES, H.C. Caracterização dos pigmentos antociânicos de diferentes cultivares de acerola (Malpighia glabra) por CLAE. In: LATIN AMERICAN CONGRESS ON CHOMATOGRAPHY, 7., 1988, Águas de São Pedro. Book of Abstracts... São Carlos: USP, 1988. p.155.

SILVA, M.F.V.; MENEZES, H.C.; GUEDES, M.C. Efeito de diferentes tratamentos térmicos sobre as antocianinas na polpa de acerola. In: SIMPÓSIO LATINO AMERICANO DE CIÊNCIA E TECNOLOGIA DE ALIMENTOS, 3., 1999, Campinas. Anais... Campinas: UNICAMP, 1999. p.152-153.

TIMBERLAKE, C.F. Anthocyanins-occurrence, extraction and chemistry. Food Chemistry, Oxford, v.5, p.69- 80, 1980.

VENDRANINI, A. L. do A.; TRUGO, L. C. Fracionamento de identificão de compostos fenólicos na acerola (Malpighia punicifolia L.).

In: CONGRESSO BRASILEIRO DE CIÊNCIAS E TECNOLOGIA DE ALIMENTOS, 17., 2000, Fortaleza. Anais... Fortaleza: Sociedade Brasileira de Ciência e Tecnologia de Alimentos, 2000. v. 2, p. 5. 217. 